Pricing and Efficiency Decisions for Letter and Parcel Markets when Industrial Relations Matter

Philippe De Donder, Frank Rodriguez and Soterios Soteri 


\title{
Pricing and Efficiency Decisions for Letter and Parcel Markets when Industrial Relations Matter ${ }^{1}$
}

\author{
Philippe De Donder (Toulouse School of Economics), Frank Rodriguez (Oxera \\ Consulting LLP) and Soterios Soteri (Royal Mail Group)
}

\section{Introduction}

A key feature of postal markets today is the changing mix of mail sent by customers and processed by postal operators. While the demand for letters is in decline, predominantly because of e-substitution, parcel traffic is increasing as a result of the rapid growth of ecommerce. Universal service providers (USPs) in the postal sector serve both markets. In the former, universal service obligations (USOs) are in place and regulators and private shareholders, where the USP is privatized, press for improvements in efficiency, in the case of regulators through the promotion of competition and the application of regulatory controls. In the latter, markets are highly competitive with parcel companies offering a wide range of differentiated services. In both markets, USPs are under pressure to increase efficiency and lower costs and prices to maintain financial viability and sustain profitability. But postal operations, and delivery in particular, are labor intensive. The pressure to raise efficiency and lower costs both current and future poses a threat of industrial action by employees and the effects of such action are likely to be greater the higher the rate at which USPs seek to increase efficiency.

In a previous paper we considered some of these issues and trade-offs through a two-period model with a particular focus on mail as a whole, delivered through the universal service network, and the regulatory constraints under which USPs operate (De Donder et al., 2017). The current paper explores these themes in more detail and extends that earlier model in two main ways. First, the model considers separately letter and (bulk or contract) parcel services of the USP delivered through its universal service network. This separation allows the analysis to reflect the significant differences between the letter and parcel markets both in terms of their long term growth prospects and their cost structure. Second, the model expands its treatment of the effects of a potential strike on volumes and profitability, by allowing for an explicit diversion of traffic at the time of a strike from the USP to competitors. Further, the higher (lower) the USP's target to improve efficiency, the greater (smaller) the likely change to work practices and reduction in its workforce and so resistance to such changes by labor, increasing (reducing) the adverse impact of a strike on the USP's mail volume.

The paper is structured as follows. Section 2 outlines our model. Section 3 illustrates its operation with some numerical simulations based on a calibrated version of the model while Section 4 reports results for sensitivities on some key assumptions. Section 5 concludes. An appendix provides more detail on the analytics of the model and its calibration.

\section{The Model}

\subsection{Operators and Markets}

The model we develop extends the one presented in De Donder et al (2017). In order for this paper to be self-contained, we outline all the building blocks of the model and further develop the model analytically in Appendix 1.

\footnotetext{
${ }^{1}$ The views expressed in this paper are those of the authors and do not necessarily reflect those of their affiliated organizations.
} 
There are two types of postal operators: a USP, denoted by $I$, and a set of competitors, denoted by $E$. There are four postal services: single-piece (SP) mail, bulk letters (BL), an access service for delivery of competitors' BL through the USP's network, and contract parcels (CP). We consider two delivery areas: a low cost urban one $(U)$, and a high cost, rural one $(R)$.

We describe the four postal services sequentially. The USP is subject to a USO to provide SP mail of a given quality and at the same price delivering to all addresses in both delivery areas. The USP enjoys a de facto monopoly on the SP mail market as competitors do not find it profitable to offer a competing SP service with these features.

The USP faces competition on both the BL and CP markets. Competition in the BL market can be either end-to-end (E2E) or access with the USP then selling both an E2E BL product to final consumers, as well as an access service to competitors. In the case of access, each unit of competitors' BL requires one unit of access to the USP delivery network. The BL products offered by both types of operators are imperfect substitutes, whether the competitor uses access or bypasses the USP delivery network. Competitors then choose the cheapest way to deliver (i.e., they offer an E2E product if the access charge is larger than their own delivery cost, and access the USP delivery network otherwise). The competitors charge an exogenous mark-up over their marginal cost in both cases whose level reflects the intensity of competition on the BL market.

Competition on the CP market is of the E2E variety and there is no access to the USP delivery network for competitors. CP products sold by the USP and competitors are imperfect substitutes, and competitors charge an exogenous mark-up over their marginal costs. There is no substitution between SP mail, BL and CP.

Both types of operators face constant variable costs. We further assume that the USO provided by the USP translates into this operator incurring also a fixed cost.

\subsection{Timing and decisions}

We consider two periods, denoted by $\mathrm{P}_{1}$ and $\mathrm{P}_{2}$. All firms announce their price for $\mathrm{P}_{1}$ at the beginning of $\mathrm{P}_{1}$. The USP chooses its $\mathrm{BL}$ and CP prices in order to maximize its profit. The USP faces two regulatory constraints on its prices. First, the SP mail price is capped at $\bar{p}$ by the regulator (constraint C1) so that the USP is able to make a normal rate of return (that is, it breaks-even achieving zero economic profit and the margin made by selling all four types of services exactly covers the fixed cost of the USP). Second, the regulator sets a constraint on the USP's access prices in the BL market. It can either cap the USP's access price at a percentage mark-up over the USP's downstream cost (constraint 2a) or set a margin squeeze constraint, such that the difference between the USP's BL price and access charge cannot be smaller than the USP's BL upstream cost (constraint 2b). The choice of constraint by the regulator impacts materially on whether entrants offer a BL service through access or bypass. ${ }^{2}$ As explained above, competitors set prices by posting an exogenous mark-up over their variable costs.

The regulator then announces the specifics of the price constraints it will set during the next regulatory cycle, which is assumed to last five years, based on its assessment of prospects for mail demand and efficiency improvements. The regulator assesses the value of $e$, which is

\footnotetext{
${ }^{2}$ There is a formal statement of these constraints in Appendix 1 where we also consider constraint C3: that the difference between the SP mail price and the USP's BL price in any given zone must be greater than the upstream preparation costs of the USP's BL final customers.
} 
the yearly percentage reduction in (both variable and fixed) costs the USP could be expected to attain and sets the price cap $\bar{p}$ and access price constraint for the second regulatory cycle. Reductions in costs may arise from improvements in productivity or lower wage costs or a mix of both factors. The value of $e$ is assumed to be obtained from a rigorous efficiency review process undertaken in $\mathrm{P}_{1}$ that yields a challenging yet achievable estimate in $\mathrm{P}_{2}$.

The USP then announces (in $\mathrm{P}_{1}$ ) efficiency targets to be achieved during the next regulatory cycle, but the value of $e$ it chooses need not equal that used by the regulator to set its price constraint $\bar{p}$. The announcement of efficiency targets by the USP is associated with risks of industrial action. $P_{1 S}$ (respectively, $P_{1 N S}$ ) denotes the first-period when a strike does (respectively, does not) occur and it is assumed the regulator does not take into account the possibility of a strike when assessing its value of $e$.

If a strike occurs, the USP is assumed not to adapt its prices in $\mathrm{P}_{1}{ }^{3}$ The strike results in a decrease of $\gamma_{1}^{L}(e) \%$ in the USP's SP and BL volumes in $\mathrm{P}_{1}$. If competitors use access in the BL market, they are similarly affected by the strike. If they deliver BL themselves, then a fraction $\beta_{1}^{L}$ of the USP volume decrease diverts to competitors, whose volumes increase by $\beta_{1}^{L} \gamma_{1}^{L}(e) \%$ of the USP volumes. In the CP market, the USP volumes decrease by $\gamma_{1}^{P}(e)$ percent, but a fraction $\beta_{1}^{P}$ of this decrease diverts to competitors, whose volumes increase by $\beta_{1}^{P} \gamma_{1}^{P}(e) \%$ of the USP volumes (see Appendix 1 for precise statements). The functions $\gamma_{1}^{L}$ and $\gamma_{1}^{P}$ are both increasing in $e$, as the announcement of a larger decrease in costs is likely to result in more severe industrial action. ${ }^{4}$

We now move to $\mathrm{P}_{2}$. The model assumes that the USP efficiency targets announced in $\mathrm{P}_{1}$ are achieved in $\mathrm{P}_{2}$ whether or not a strike occurred in $\mathrm{P}_{1}$ and, with a regulatory cycle of five years, USP costs decrease by $5 e$ by the end of $\mathrm{P}_{2}$. For simplicity, competitors' costs are assumed to be the same as in $\mathrm{P}_{1}$, such that $e$ can be interpreted as the amount by which the USP lowers its costs each year relative to competitors. Market volumes are assumed to trend similarly for all operators, independent of postal prices. The total variation in these is given by the parameter $\lambda$ so that, for any given prices, mail volumes are $\lambda \%$ higher in $\mathrm{P}_{2}$ than in $\mathrm{P}_{1}$. We assume (see Appendices 1 and 3 ) that letter volumes face a negative trend ( $\lambda=\lambda_{L}<0$, due to e-substitution) while parcel volumes benefit from a positive trend ( $\lambda=\lambda_{P}>0$, due to e-commerce).

When a strike occurred in $\mathrm{P}_{1}$, USP SP volumes decrease by $\gamma_{2}^{L}(e) \%$ in $\mathrm{P}_{2}$. We assume that $\gamma_{2}^{L}(e)<\gamma_{1}^{L}(e)$ since there is likely to be a reduced but continuing effect from the strike in $\mathrm{P}_{1}$ due, for example, to additional e-substitution. The impact of a strike in $\mathrm{P}_{1}$ on BL volumes depends on the type of competition. If competitors use access to the USP delivery network, they are affected in the same way as the USP by the strike, with volumes decreasing by $\gamma_{2}^{L}(e) \%$ for both in $\mathrm{P}_{2}$. If competition occurs with bypass, we contrast two scenarios (see Appendix 1 for more details). The "Full Reversion" scenario is equivalent to what happens

\footnotetext{
${ }^{3}$ As explained at the end of this section, it would not wish to change them anyway.

${ }^{4}$ When choosing whether to access or bypass the USP delivery network, competitors do not anticipate that the form of competition they choose will affect the volume of their demand in case of a strike. We leave this extension for future research.
} 
with access, with volumes of both operators decreasing by $\gamma_{2}^{L}(e) \%$. Under the "Full Retention" scenario, market BL volumes also decrease, but there is also substitution in favor of the competitors.

CP market volumes in $\mathrm{P}_{2}$ are not affected by whether a strike occurred or not in $\mathrm{P}_{1}$ but again we contrast two scenarios regarding the volumes of the USP when a strike occurred in $\mathrm{P}_{1}$. Under Full Reversion, traffic lost by the USP to competitors in $\mathrm{P}_{1}$ following a strike is assumed to revert in full in $\mathrm{P}_{2}$ to the USP. Under Full Retention, a fraction $\gamma_{2}^{P}(e)$ of USP volumes diverts to competitors. Here also, we assume that $\gamma_{2}^{P}(e)$ is increasing in $e$ with $\gamma_{2}^{P}(e)<\gamma_{1}^{P}(e)$.

$P_{2 S}$ (respectively, $P_{2 N S}$ ) denotes the second-period when a strike did (respectively, did not) occur in $\mathrm{P}_{1}$. The USP then chooses prices for $\mathrm{P}_{2}$ to maximize profit in $\mathrm{P}_{2}$, subject to the price constraints C1 to C3 (see Appendix 1), its costs (given its choice of $e$ ) and market demand during $\mathrm{P}_{2}$. The USP of course knows whether a strike occurred in $\mathrm{P}_{1}$, and can charge different prices accordingly. Competitors post their prices for $\mathrm{P}_{2}$ simultaneously.

The USP's profit is denoted by $\pi_{k j}$ in period $k=\{1,2\}$ whether a strike occurred in $\mathrm{P}_{1}(j=$ $S$ ) or not $(j=N S)$. Observe that the same set of USP prices maximize $\pi_{k S}$ and $\pi_{k N S}$ in the model because the impact of a strike is to scale down volumes by a given percentage, and prices which maximize a specific function also maximize a fraction of this function. So, prices will not differ between $\mathrm{P}_{25}$ and $\mathrm{P}_{2 \mathrm{NS}}$, and it does not matter whether first-period prices maximize $\pi_{1 S}, \pi_{1 N S}$ or any linear combination of the two. Note that prices in $\mathrm{P}_{1}$ do not affect profit levels in $\mathrm{P}_{2}$ (since they do not affect the strike outcome), so the assumption that prices in period $k=\{1,2\}$ maximize profit in the same period $k$ is innocuous, since the same sets of prices also maximize any weighted combination of profits in the two periods. Appendix 2 explains how the USP weighs the two periods to evaluate overall discounted profit when considering the value of $e$ to set in period 1 . The weights placed on profit in $\mathrm{P}_{1}$ and $\mathrm{P}_{2}$ are denoted respectively by $w_{1}$ and $w_{2}$ and discounted profit when a strike occurs is denoted by:

$$
\pi_{S}=w_{1} \pi_{1 S}+w_{2} \pi_{2 S},
$$

while the discounted profit where a strike does not occur is:

$$
\pi_{N S}=w_{1} \pi_{1 N S}+w_{2} \pi_{2 N S} \text {. }
$$

\section{Results from the Model: Low Access Prices Case}

For reasons of space, we illustrate the operation and results of the model for one of the two cases considered numerically in De Donder et al. (2017), namely that of low access prices in the BL market. Here constraint C2a determines the USP's access prices and we assume that the regulator sets the value of the mark-up on the USP' downstream cost at $10 \%$, the regulator's aim being to encourage competitive entry upstream in the value chain. We then obtain that the constraint $\mathrm{C} 3$ is not binding in the equilibria reported in this section. ${ }^{5}$ In addition to limiting the USP's access prices, the regulator sets constraint $\mathrm{C} 1$, the price cap on SP mail, at a level (assuming no strike) that allows the USP to achieve zero economic profit

\footnotetext{
${ }^{5}$ In simulations where the regulator constrains access prices using the margin squeeze constraint $\mathrm{C} 2 \mathrm{~b}$ we find that both $\mathrm{C} 2 \mathrm{~b}$ and $\mathrm{C} 3$ bind and competitors enter the BL market in the urban area through E2E competition rather than access.
} 
when it sets profit-maximizing prices in the BL and CP markets. Appendix 3 sets out the calibration assumptions applied in deriving the results reported in this section, which are based on published information or assumptions reflecting broadly the operation of postal markets in Europe.

Results are reported in Table 1 . The first column presents results for $\mathrm{P}_{1}$ in the case where no strike occurs in that period. In the BL market, entrants price at a mark-up of $2 \%$ over their variable costs including the access charge. The USP sets its profit-maximizing prices above those offered by entrants with prices for both being higher in the rural area than the urban, reflecting differences in delivery costs. By contrast, in the CP market competitors offer a higher specification service to senders than the USP and price at a mark-up of $3 \%$ over their variable costs. The USP's profit-maximizing prices in the CP market are then below those of competitors with higher prices again in the rural area reflecting cost differences. In both the BL and CP markets, competitors gain more than $50 \%$ of the market although delivery of all $\mathrm{BL}$ is by the USP. At the base case calibration values, the price cap on SP mail, $\bar{p}$, in $\mathrm{P}_{1}$ that would be required to be set by the regulator to allow the USP to breakeven is $1.49 €$ (against a fully allocated cost, or FAC, of 1). The cap is binding at equilibrium.

The second column of Table 1 reports results for $\mathrm{P}_{1}$ for the case where there is a strike at the USP in $\mathrm{P}_{1}$. As outlined in Section 2, prices are unchanged from their no strike values. The effect of the strike on volumes depends on the efficiency target the USP is seeking to achieve in $\mathrm{P}_{2}$. The column reports outcomes for the case where that target is a $2 \%$ per annum improvement in efficiency. From Appendix 3, this results in a 12\% loss in letter volume for both the USP and entrants as no access service can be offered either to non-USP operators during a strike. For parcels, the loss of volume by the USP is higher at $24 \%$ as alternative services are on offer from competitors and, of the USP's volume loss, some $80 \%$ is assumed to switch to competitors so increasing their market share in $\mathrm{P}_{1}$. As a result of these volume losses, at these calibration values the USP makes a loss of economic profit of $335 \mathrm{~m} €$ and there is a drop in the net consumer surplus enjoyed by senders of SP mail. While prices in $\mathrm{P}_{1}$ are unaffected by the USP's target for efficiency in $\mathrm{P}_{2}$, the volume losses from a strike increase (decline) as that target increases (declines). For example, and although not shown in Table 1, from Appendix 3, if the USP were to seek a higher rate of efficiency improvement of $3 \%$ per annum in $\mathrm{P}_{2}$ and a strike were to occur, the reduction in all letter volumes in $\mathrm{P}_{1}$ would be $16 \%$ and, of its parcels traffic, $32 \%$ ( $80 \%$ of which would switch to competitors). Its loss of economic profit would increase to $447 \mathrm{~m} €$.

Letter volumes are declining by significant amounts in most developed countries while parcel volumes are growing rapidly. To reflect these trends in the numerical simulation of the model, in $\mathrm{P}_{2}$ it is assumed that both the SP and BL markets contract by $20 \%$ compared with the no strike volume level in $\mathrm{P}_{1}$ while the CP market expands by $20 \%$. The USP seeks to reduce its costs relative to competitors and set profit-maximizing prices in the BL and CP markets. Table 1 reports these prices in the case where the USP achieves a $2 \%$ per annum reduction in its costs $\left(10 \%\right.$ in total by $\left.\mathrm{P}_{2}\right)$ consistent with an assumed value the regulator assesses is a reasonable rate of efficiency improvement by the USP. The assumed passing through in full of lower USP costs in delivery into reduced access prices results in competitor prices declining by almost $10 \%$. It is profit-maximizing for the USP to reduce its BL prices by about $7 \%$ (for example, to 0.274 in the urban area from 0.295 ) rather than $10 \%$ but BL's share of contribution in $\mathrm{P}_{2}$ to the reduced fixed cost of 2.16bn€ still declines marginally compared with $\mathrm{P}_{1}$. 


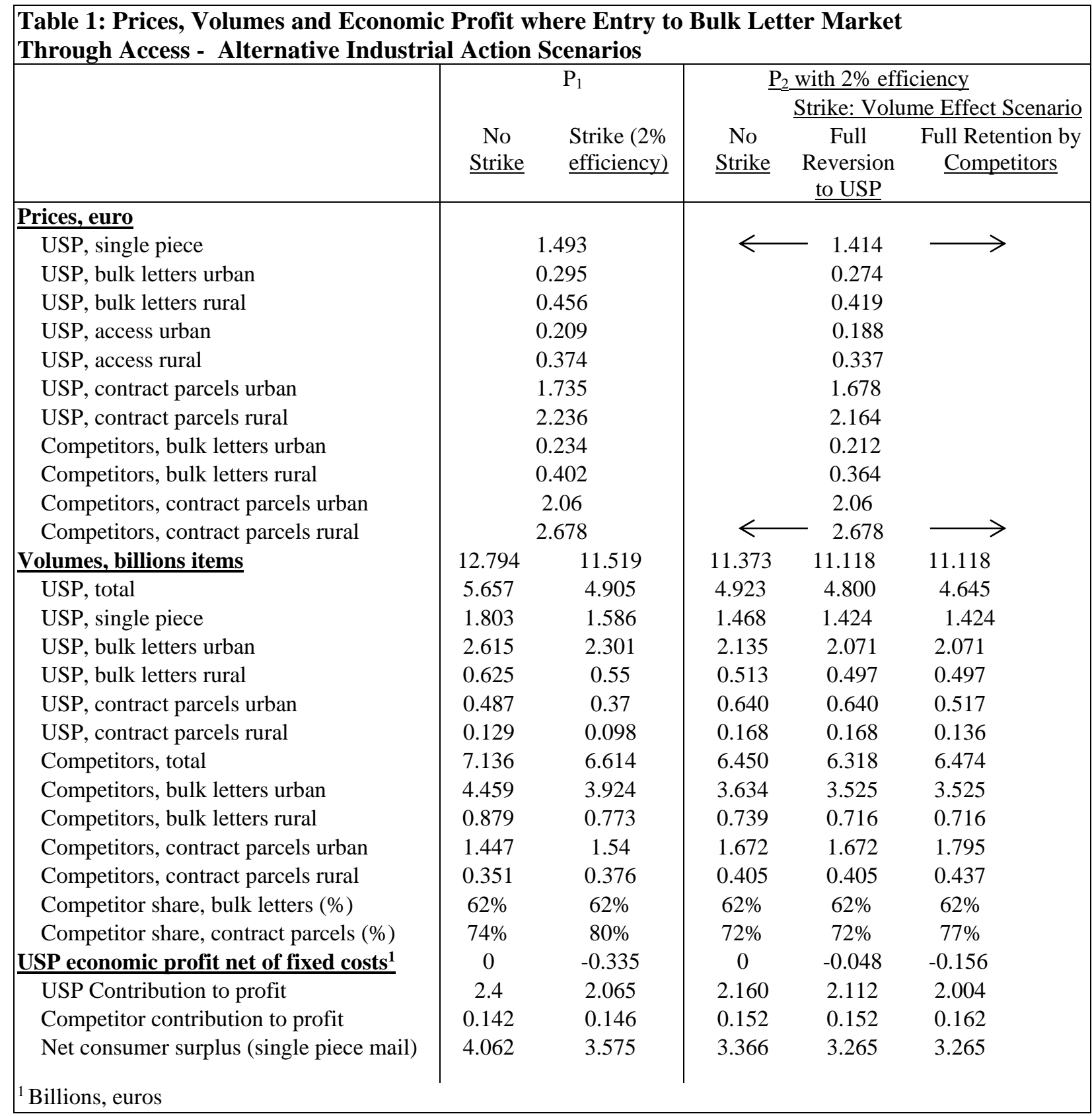

In the CP market where it is assumed also that the USP's costs decline by $10 \%$ relative to competitors in $\mathrm{P}_{2}$, the USP's profit-maximizing prices are only about $3 \%$ below those in $\mathrm{P}_{1}$ (for example, 1.678 in the urban area from 1.735). This price cut leads the USP to gain market share and together with underlying growth in the CP market allows the USP to increase its volumes and raise its contribution to profit in $\mathrm{P}_{2}$ from parcels traffic. At the model's base case calibration values these effects are sufficient to reduce the requirement from the SP market for contribution to fund the fixed cost of universal service. Consequently, the regulator can lower the price cap on SP mail by about 5\% to 1.414 for the USP to breakeven in $\mathrm{P}_{2}$, albeit that this reduction is less than in USP costs.

The two final columns in Table 1 report results for $\mathrm{P}_{2}$ for the case where a strike occurs in $\mathrm{P}_{1}$ while the USP is targeting an efficiency improvement of $2 \%$ per annum in $\mathrm{P}_{2}$. Two cases are reported. In the first, losses in volumes to competitors in the CP market from the strike in $\mathrm{P}_{1}$ all revert to the USP in $\mathrm{P}_{2}$ although there are some continuing losses in letter demand for the 
USP due to an assumption of increased e-substitution resulting from the strike. In the second, in addition to continuing losses in letter demand due to e-substitution, competitors in the CP market retain in $\mathrm{P}_{2}$ proportionately all of the volume they gained during the strike in $\mathrm{P}$. Equilibrium prices are the same with or without a strike in $\mathrm{P}_{1}$. In the full reversion case, the impact on letter volumes leads the USP make a loss of $48 \mathrm{~m} €$. There is also a loss of net consumer surplus on SP mail. In the full retention case, additionally the USP loses market share and contribution from the CP market resulting in a larger loss of $156 \mathrm{~m} €$.

Although it is assumed that the regulator sets the SP price cap for $\mathrm{P}_{2}$ on the basis that the USP reduces its costs by $2 \%$ per annum, the USP may aim for a higher or lower rate of efficiency improvement. For example, if it chose to target a 3\% improvement, its costs in $\mathrm{P}_{2}$ would be lower and so would its prices (although, as in the case of a $2 \%$ improvement, by less than the full reduction in costs). However, if a strike were to occur in $\mathrm{P}_{1}$, its impact on the USP's volumes in both $\mathrm{P}_{1}$ and $\mathrm{P}_{2}$ would be more substantial. The cost reduction effect raises profitability compared with the $2 \%$ case while the strike effect lowers it. At a $3 \%$ reduction without a strike, the USP's volumes and contribution per unit would be higher as would its economic profit in $\mathrm{P}_{2}$ at $212 \mathrm{~m} €$. However, if a strike were to occur in $\mathrm{P}_{1}$ in achieving this higher rate of efficiency improvement, this gain would be reduced to $146 \mathrm{~m} €$ in the full reversion case and to a loss of $11 \mathrm{~m} €$ where there is full retention in $\mathrm{P}_{2}$ of volumes gained from the USP by CP operators in $\mathrm{P}_{1}$.

The relationship between efficiency, $e$, and the USP's economic profit at equilibrium prices is examined further in Figure 1. Profits in $\mathrm{P}_{1}$ and $\mathrm{P}_{2}$ in the cases where there is no strike in $\mathrm{P}_{1}$ $(\pi \mathrm{NS})$, a strike in $\mathrm{P}_{1}$ with full reversion of CP volumes to the USP in $\mathrm{P}_{2}$ ( $\pi$ s full reversion) and a strike in $\mathrm{P}_{1}$ with full retention of $\mathrm{CP}$ volumes by competitors in $\mathrm{P}_{2}$ ( $\pi$ s full retention) are discounted to their present value in $\mathrm{P}_{1}$ using the approximate method outlined in Appendix 2. Figure 1 plots the present value of economic profits for the three cases at each value of $e$. Table 1 reported these prices and associated volumes for just one value of $e, 2 \%$. The schedule for the no strike case ( $\pi \mathrm{NS})$ rises approximately linearly in $e$. Lowering its costs allows the USP to reduce its prices relative to competitors so that, as reported in Table 1, it can both gain market share and raise profit contribution per unit. As its costs decline, the USP's economic profit increases being zero at $2 \%$ (point A) by construction from the setting of the price cap on SP mail by the regulator. Failure to secure an efficiency improvement of at least $2 \%$ would lead to the USP making negative economic profits.

The schedules for the two strike cases reflect a trade-off for the USP. A higher efficiency target for $\mathrm{P}_{2}$, if it leads to a strike in $\mathrm{P}_{1}$, results in a greater loss of profit in $\mathrm{P}_{1}$. But in $\mathrm{P}_{2}$, the USP's costs and hence prices are lower so that contribution per unit and volumes increase raising profitability. At the base case calibration values the second of these effects is the stronger in the full reversion case ( $\pi$ s full reversion) and the present value of losses declines as $e$ rises. In the full retention case ( $\pi$ s full retention) the two effects roughly cancel over the range of values of $e$ reported in the figure and the present value of losses is broadly flat. 
Figure 1: USP's Economic Profit - No strike, Strike Full Reversion \& Full Retention Scenarios

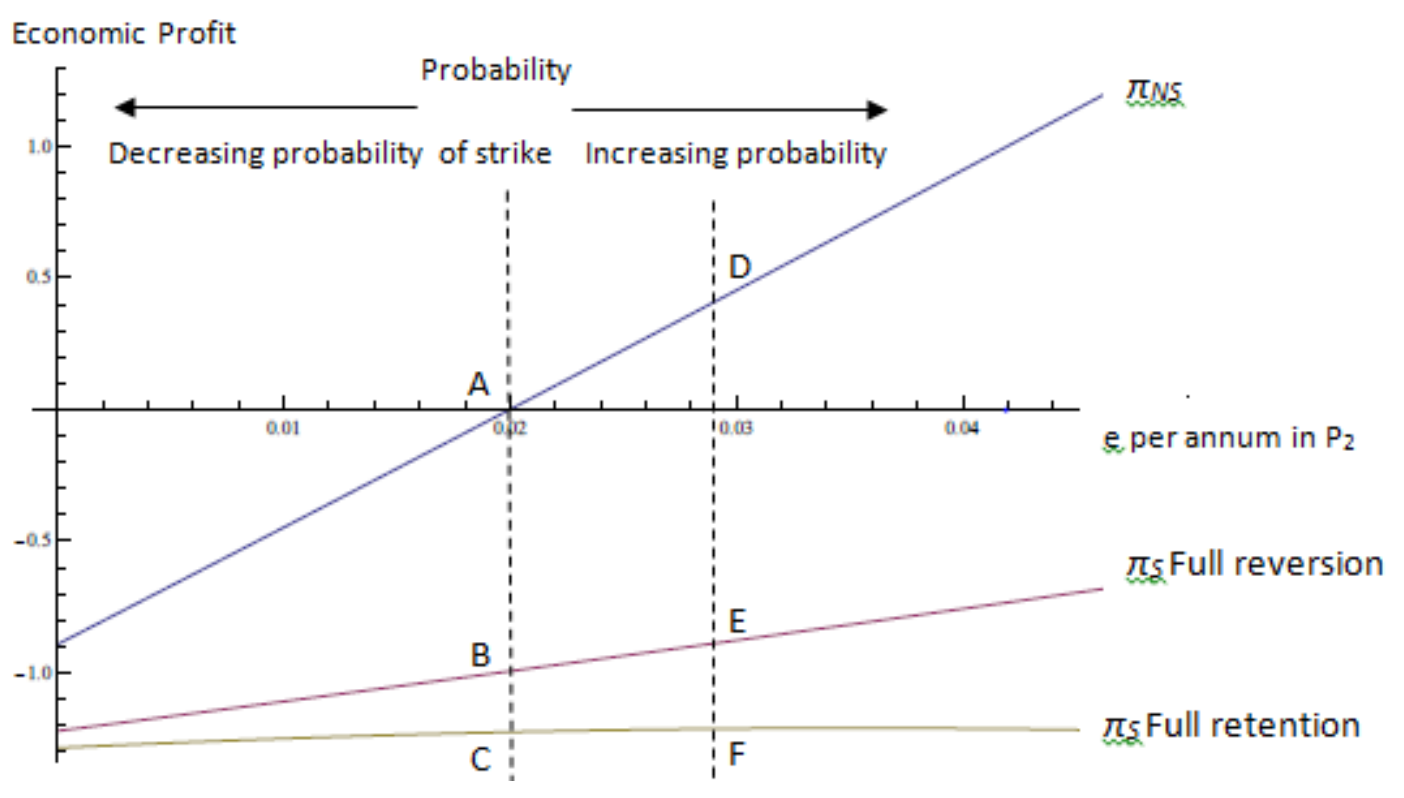

\section{Sensitivities on Key Assumptions}

It is important to assess the sensitivity of the results in Section 3 to plausible alternative assumptions for key variables and parameters in the model. In this section we consider four main groups of assumptions and their effects on economic profit: assumptions on volumes in $\mathrm{P}_{2}$ compared with $\mathrm{P}_{1}$; the impact of a strike in $\mathrm{P}_{1}$ on the USP's volumes; the discount rate used to calculate the present value of profits; and the efficiency target in $\mathrm{P}_{2}$. The main results are summarized in Table 2.

The first row records the present value of economic profits in the base case. These have been calculated at a discount rate of $10 \%$ using the approximate method outlined at Appendix 2. In the no strike case the USP achieves breakeven in both $\mathrm{P}_{1}$ and $\mathrm{P}_{2}$ by construction from the assumption that the regulator sets a price cap for SP mail to facilitate this outcome (point $\mathrm{A}$, Figure 1). As reported in Table 1 also, a strike in $\mathrm{P}_{1}$ in the base case is modelled to result in a loss of $335 \mathrm{~m} €$. Where volume lost in that period reverts fully to the USP in $\mathrm{P}_{2}$ there is a loss to the USP in $\mathrm{P}_{2}$ of $48 \mathrm{~m} €$ while full retention of these volume gains by competitors in $\mathrm{P}_{2}$ implies a larger loss of $156 \mathrm{~m} €$. The present values of these two scenarios are, respectively, 0.995bn€ (point B) and -1.266bn€ (point C).

The remaining rows of Table 2 report the impact of sensitivities to key assumptions as changes in the economic profit of the USP from the base case values. In the first of these, letter volumes are assumed to be $10 \%$ lower than the base case in $\mathrm{P}_{2}$ (and so $30 \%$ below their level in $\mathrm{P}_{1}$ ) and lower than expected by the USP or the regulator in setting its price cap on SP mail which it cannot then adjust to compensate for this unexpected shortfall. In present value terms the shortfall in volumes would lead to a loss of a little over $400 \mathrm{~m} €$ whether or not a strike occurred in $\mathrm{P} 1$. As discussed in Section 2, the USP's profit-maximizing prices on its BL service would have been unaffected by the decline in volumes while access prices are set at the USP's downstream cost in $\mathrm{P}_{2}$ plus a $10 \%$ margin. Relative to the base case the impact in the strike scenarios is slightly less than the no strike scenario because a strike is assumed to increase e-substitution in $\mathrm{P}_{2}$ and so reduce the volumes against which the $10 \%$ shortfall occurs. Note that if the regulator had expected letter volumes to decline by $30 \%$ rather than $20 \%$, it would have been necessary to set a higher price cap on SP mail to allow the USP to 
breakeven. In this case the present value of economic profit would be zero but senders of SP mail would suffer a loss of net consumer surplus due to the higher SP price.

In the second sensitivity, parcel volumes are assumed to outturn at $10 \%$ less than expected and increase by only $10 \%$ by the end of $\mathrm{P}_{2}$ rather than $20 \%$ as assumed in the base case. The prices set by the USP on its CP service are profit-maximizing but the reduced volume of parcels results in a lower contribution to the USP's profit which cannot be made up by the USP from that service. Relative to the base case, the present value of this shortfall is about $100 \mathrm{~m} €$ and smaller than that from a $10 \%$ shortfall in letters as CP mail is proportionately a smaller contributor to the USP's profit. Again, the change in profitability in the full retention strike scenario is smaller for under this the USP has lower CP volumes against which the $10 \%$ shortfall occurs due to the strike.

The third sensitivity examines the effect of the strike impact on volumes being $25 \%$ higher than assumed in the base. While the effect in $\mathrm{P}_{1}$ in the two strike scenarios is the same, the full retention by competitors in $\mathrm{P}_{2}$ of volumes gained in $\mathrm{P}_{1}$ has a greater negative impact on the USP's profit. Both of the strike scenarios are significant with that for full retention adding losses of over $300 \mathrm{~m} €$ relative to the base case.

Each of the three sensitivities on volumes has been on cases where it has been assumed that these are lower than in the base case. Within the model, if these effects had been in the opposite direction and it was assumed that volumes were higher by the same amounts then the effects on profitability would have been reversed and to an approximation the changes above and below the base case reported in Table 2 are symmetric.

\begin{tabular}{|c|c|c|c|}
\hline & \multirow[b]{2}{*}{$\begin{array}{c}\text { No } \\
\text { Strike }\end{array}$} & \multicolumn{2}{|c|}{ Strike Volume Effect Scenario } \\
\hline & & $\begin{array}{c}\text { Full } \\
\text { Reversion } \\
\text { to USP }\end{array}$ & $\begin{array}{c}\text { Full Retention } \\
\text { by Competitors }\end{array}$ \\
\hline Base Case (2\% Efficiency in $\left.\mathrm{P}_{2}\right)$ & 0 & -0.995 & -1.266 \\
\hline \multicolumn{4}{|l|}{ Changes in Economic Profit from Base Case: } \\
\hline Letter Volumes lower by $10 \%$ in $\mathrm{P}_{2}{ }^{2}$ & -0.428 & -0.413 & -0.415 \\
\hline Parcel Volumes lower by $10 \%$ in $\mathrm{P}_{2}^{2}$ & -0.100 & -0.100 & -0.081 \\
\hline Strike Impact on Volumes higher by $25 \%{ }^{2}$ & 0 & -0.249 & -0.307 \\
\hline Discount Rate lowered from $10 \%$ to $5 \%$ & 0 & -0.065 & -0.103 \\
\hline Base Case with 3\% Efficiency in $\mathrm{P}_{2}$ & 0.453 & 0.116 & 0.012 \\
\hline
\end{tabular}

The impacts also are approximately additive. For example, in the strike scenario of full reversion of volumes to the USP, if both letter and parcel volumes had been $10 \%$ lower in $\mathrm{P}_{2}$ than assumed in the base and the strike effect higher by $25 \%$, the change in economic profit from the base would have been approximately the sum of the individual effects or about $760 \mathrm{~m} €$.

The two remaining sensitivities in Table 2 are rather different in nature. The discount rate used to calculate present values in the base case is $10 \%$. The sensitivity considers the impact of reducing this to $5 \%$ which clearly has no effect in the no strike case but values losses in $\mathrm{P}_{2}$ for the two strike scenarios more highly and worsens the loss of economic profit relative to 
the base. However, the impact of this change in the discount rate is not large reflecting the fact that the impact of a strike on profitability in the base case is assumed in the calibration to be greater in $\mathrm{P}_{1}$ than $\mathrm{P}_{2}$. The final row of Table 2 considers the impact on economic profit of increasing the target rate of efficiency improvement by the USP in $\mathrm{P}_{2}$ from $2 \%$ in the base case to $3 \%$. These results were also reported graphically in Figure 1. A higher rate of efficiency improvement by the USP in $\mathrm{P}_{2}$ over that assumed by the regulator results in the USP lowering its costs and increasing its profitability if no strike from its SP, BL and CP services (point D). However, if a strike were to occur in the process of achieving these increased efficiency gains its negative effect on profits would be greater than in the case of a $2 \%$ efficiency target. In the full retention case reported in Table 2 the negative impact of a strike as assumed under the base case would more or less negate any gain in profitability from higher efficiency gains (point F) while in the full reversion case this gain would be modest (point E).

\section{Conclusions}

This paper has adopted and extended the framework developed by De Donder et al. (2017) to examine the challenge faced by a USP aiming to deliver efficiency gains, maintain financial viability and sustain profitability. In particular, our paper developed and calibrated a twoperiod model $\left(\mathrm{P}_{1}\right.$ and $\left.\mathrm{P}_{2}\right)$ to examine the challenges faced by a USP aiming to deliver efficiency gains in the future but which may lead to costly strike action in advance of these being achieved.

Similar to De Donder et al. (2017) the model structure and assumptions consist of a number of key elements. First, letter volumes are in long term structural decline due to e-substitution. Second, there is a requirement for the USP to meet a pre-specified USO but entrants are not required to do so. Third, the USP is subject to price controls set by a regulator. Fourth, fixed costs are inherent in meeting the USO. However, we extend and develop the model in two important ways. In particular, we separate the letter and parcel services of the USP delivered through its universal service network to take account of significant differences in their longer term growth prospects and impacts on their respective volumes from a strike. In addition, we link the potential cost of strike action, which is assumed to occur in $\mathrm{P}_{1}$, to the magnitude of targeted efficiency gains that accrue in $\mathrm{P}_{2}$ to allow a richer modelling of potential strike impacts.

Our model assumes a high level of competition in the bulk letters (BL) and contract parcels (CP) markets, with the USP competing against other letter and parcel operators, and that the regulator intervenes in the BL market by constraining the access prices the USP can set in delivering BL for competitors. In the paper we examine through a simulation of the model the case where these constraints lead to low access prices resulting in upstream BL competition in all geographies (rural and urban) and no bypass competition. In both the BL and CP markets, competitors gain more than $50 \%$ of the market in the model although, in the former, delivery of all BL is by the USP. Competition in the BL market leads to significant differences in prices between single-piece and BL traffic with competitors offering lower BL prices than the USP. However, as parcel competitors are assumed to offer a higher specification service their prices are higher than those of the USP.

The USP is assumed to operate within a price control structure that requires a specific rate of efficiency to be achieved to maintain a normal rate of return (zero economic profit) during the next price control period if no strike takes place. In such an environment the USP is assumed to be able to achieve a higher/lower efficiency than this specific level but runs the 
risk of an increasing/decreasing risk of industrial action whose potential costs, if a strike is triggered, increase with the scale of targeted efficiency.

In the event of a strike being avoided our results suggest that the USP's profit could increase considerably if it were to target higher rates of efficiency. However, our modelling also indicates that if a strike occurs the USP will suffer significant losses that cannot be recouped during the price control period. The main factors underpinning this result are two-fold. First, industrial action results in lost volume and revenue during the strike which over the longer term encourages further losses as both senders and recipients of mail switch away from physical mail and adopt electronic alternatives. Second, a significant proportion of parcel traffic is assumed to switch to existing parcel competitors. With regards to the latter, the extent of the loss suffered by the USP will depend on the quantity of contract parcels the USP loses during the strike period (that is, switch to competitors or customers decide to not send in $\mathrm{P}_{1}$ ) and how much of this returns when the strike is over as well as efficiency gains achieved (in $\mathrm{P}_{2}$ ).

The paper concludes with a number of sensitivities being run to assess the potential impact of plausible alternative assumptions. Four in particular, are worth noting: first, the impact of lower than expected letter and parcel volumes (due, say, to changes in market conditions) could have a substantial negative impact on the USP's finances. Second, the industrial action sensitivity suggests that if the extent of traffic loss associated with strike action differed from the base case, this could impact the results considerably. However, given the high losses assumed under the two base case strike scenarios this suggests the final outcome could be significantly worse or just somewhat less bad. Third, the lower discount rate sensitivity results in present values that give greater weight to the value of losses in $\mathrm{P}_{2}$ and worsens the loss of economic profit relative to the base case. Fourth, achieving higher efficiency rates and avoiding strike action can result in considerably higher levels of economic profit, but much of this gain can be lost if securing these efficiency improvements results in significant industrial action.

\section{$\underline{\text { Appendix }}$}

\section{1) Analytical model.}

The net utility that consumers in zone $i \in\{U, R\}$ obtain from consuming quantity $x$ of SP mail at unit price $p$ is denoted by $u_{i}(x)-p x$.

The demand function for SP mail in zone $i$ is obtained by maximizing utility with respect to $x$, and is denoted by $x_{i}(p)$. Utility is quadratic in quantities, so that the demand function is linear and of the form $x(p)=\alpha-\beta p$. The utility function $u_{i}(x)$ is calibrated (see Appendix 3) and used to obtain the demand function in $\mathrm{P}_{1 \mathrm{NS}}$. In $\mathrm{P}_{1 \mathrm{~s}}$, demand is given $\left(1-\gamma_{1}^{L}(e)\right) x(p)$. In $\mathrm{P}_{2 \mathrm{NS}}$, volumes are given by $\left(1+\lambda_{L}\right) x(p)$ while they are given by $\left(1+\lambda_{L}\right)\left(1-\gamma_{2}^{L}(e)\right) x(p)$ in $\mathrm{P}_{2 \mathrm{~S}}$.

The unit variable cost for SP mail is denoted by $c_{i}$. The contribution to USP profit of SP mail in zone $i$ is then $\left(p-c_{i}\right) x_{i}(p)$ in $\mathrm{P}_{1 \mathrm{NS}}$, and is obtained similarly by replacing $x_{i}(p)$ by the relevant demand function (see above) in $\mathrm{P}_{1 \mathrm{~s}}, \mathrm{P}_{2 \mathrm{NS}}$ and $\mathrm{P}_{2 \mathrm{~S}}$. 
The net utility obtained by consumers in zone $i$ from consuming BL is $v_{i}\left(y_{i}^{I}, y_{i}^{E}\right)-q_{i}^{I} y_{i}^{I}-q_{i}^{E} y_{i}^{E}$, where $q_{i}^{j}$ denotes the consumer price operator $j \in\{I, E\}$ posts in zone $i$, and $y_{i}^{j}$ the quantity consumed of that good. The demand for goods in each zone is obtained by maximizing the consumers' utility, and is denoted by $y_{i}^{I}\left(q_{i}^{I}, q_{i}^{E}\right)$ and $y_{i}^{E}\left(q_{i}^{I}, q_{i}^{E}\right)$. Note that both operators' prices influence demand for both goods, because the function $v_{i}$ is non separable in $y_{i}^{I}$ and $y_{i}^{E}$. The utility function $v_{i}($.$) is quadratic in quantities, so that \mathrm{BL}$ demand functions are linear in prices. Appendix 3 details how we calibrate utility and demand functions for $\mathrm{BL}$ in $\mathrm{P}_{1 \mathrm{Ns}}$.

As for BL costs, $d_{i}^{j}$ denotes operator $j$ 's (constant) marginal delivery cost in zone $i$, and $b_{i}^{j}$ operator $j$ 's upstream constant unit cost in zone $i$. If the access charge $a_{i}$ is smaller than the competitor's delivery cost $d_{i}^{E}$, the competitor chooses to access the USP's delivery network in zone $i$ and charges a price $q_{i}^{E}=\left(1+m_{L}^{E}\right)\left(a_{i}+b_{i}^{E}\right)$. If $a_{i}>d_{i}^{E}$, the competitor prefers to offer an E2E product in zone $i$, whose price is $q_{i}^{E}=\left(1+m_{L}^{E}\right)\left(d_{i}^{E}+b_{i}^{E}\right)$.

In $\mathrm{P}_{1 \mathrm{~S}}$, demands are given by $\left(1-\gamma_{1}^{L}(e)\right) y_{i}^{I}\left(q_{i}^{I}, q_{i}^{E}\right)$ for the USP, and, for the competitors, by $\left(1-\gamma_{1}^{L}(e)\right) y_{i}^{E}\left(q_{i}^{I}, q_{i}^{E}\right)$ if access occurs in zone $i$, and by $y_{i}^{E}\left(q_{i}^{I}, q_{i}^{E}\right)+\beta_{1}^{L} \gamma_{1}^{L}(e) y_{i}^{I}\left(q_{i}^{I}, q_{i}^{E}\right)$ if bypass occurs. In $\mathrm{P}_{2 \mathrm{NS}}$, volumes are given by $\left(1+\lambda_{L}\right) y_{i}^{I}\left(q_{i}^{I}, q_{i}^{E}\right)$ and $\left(1+\lambda_{L}\right) y_{i}^{E}\left(q_{i}^{I}, q_{i}^{E}\right)$, respectively. Volumes in $\mathrm{P}_{2 S}$ depend on whether access takes place or not. Under access, and bypass with the "Full Reversion" scenario, volumes are given by $\left(1+\lambda_{L}\right)\left(1-\gamma_{2}^{L}(e)\right) y_{i}^{I}\left(q_{i}^{I}, q_{i}^{E}\right)$ and $\left(1+\lambda_{L}\right)\left(1-\gamma_{2}^{L}(e)\right) y_{i}^{E}\left(q_{i}^{I}, q_{i}^{E}\right)$. Under bypass and the "Full Retention" scenario, volumes are given by $\left(1+\lambda_{L}\right)\left(1-\gamma_{2}^{L \text { Ret }}(e)\right) y_{i}^{I}\left(q_{i}^{I}, q_{i}^{E}\right)$ and $\left(1+\lambda_{L}\right)\left(y_{i}^{E}\left(q_{i}^{I}, q_{i}^{E}\right)+\beta_{2}^{L} \gamma_{2}^{\text {LRet }}(e) y_{i}^{I}\left(q_{i}^{I}, q_{i}^{E}\right)\right)$.

The contribution to USP's profit of BL in zone $i$ is given by $\left(q_{i}^{I}-b_{i}^{I}-d_{i}^{I}\right) y_{i}^{I}\left(q_{i}^{I}, q_{i}^{E}\right)+\left(a_{i}-d_{i}^{I}\right) y_{i}^{E}\left(q_{i}^{I}, q_{i}^{E}\right)$ in $\mathrm{P}_{1 \mathrm{NS}}$, in case of access, and by $\left(q_{i}^{I}-b_{i}^{I}-d_{i}^{I}\right) y_{i}^{I}\left(q_{i}^{I}, q_{i}^{E}\right)$ in case of bypass. Contributions to profit are obtained similarly in $\mathrm{P}_{1 \mathrm{~s}}, \mathrm{P}_{2 \mathrm{NS}}$ and $\mathrm{P}_{2 \mathrm{~S}}$ by modifying adequately the demand functions. The contribution to competitor's profit of $\mathrm{BL}$ in zone $i$ is given by $\left(q_{i}^{E}-a_{i}-b_{i}^{E}\right) y_{i}^{E}\left(q_{i}^{I}, q_{i}^{E}\right)$ in $\mathrm{P}_{1 \mathrm{NS}}$ in case of access, and by $\left(q_{i}^{E}-d_{i}^{E}-b_{i}^{E}\right) y_{i}^{E}\left(q_{i}^{I}, q_{i}^{E}\right)$ in case of bypass. They are obtained similarly in $\mathrm{P}_{1 \mathrm{~S}}, \mathrm{P}_{2 \mathrm{NS}}$ and $\mathrm{P}_{2 \mathrm{~S}}$ by modifying adequately the demand functions.

The net utility obtained by consumers in zone $i$ from consuming CP is $w_{i}\left(z_{i}^{I}, z_{i}^{E}\right)-s_{i}^{I} z_{i}^{I}-s_{i}^{E} z_{i}^{E}$, where $s_{i}^{j}$ denotes the consumer price operator $j \in\{I, E\}$ posts in zone $i$, and $z_{i}^{j}$ the quantity consumed of that good. The demand for goods in each zone is obtained by maximizing the consumers' utility, and is denoted by $z_{i}^{I}\left(s_{i}^{I}, s_{i}^{E}\right)$ and $z_{i}^{E}\left(s_{i}^{I}, s_{i}^{E}\right)$. Note that both operators' prices influence demand for both goods, because the function $w_{i}$ is non separable in $z_{i}^{I}$ and $z_{i}^{E}$. The utility function $w_{i}($.$) is quadratic in quantities, so that \mathrm{CP}$ demand functions are linear in prices. Appendix 3 explains how we calibrate utility and demand functions for CP in $\mathrm{P}_{1 \mathrm{NS}}$. In $\mathrm{P}_{1 \mathrm{~s}}$, demands are given by $\left(1-\gamma_{1}^{P}(e)\right) z_{i}^{I}\left(s_{i}^{I}, s_{i}^{E}\right)$ and $z_{i}^{E}\left(s_{i}^{I}, s_{i}^{E}\right)+\beta_{1} \gamma_{1}^{P}(e) z_{i}^{I}\left(s_{i}^{I}, s_{i}^{E}\right)$, respectively. In $\mathrm{P}_{2 \mathrm{NS}}$, volumes are given by $\left(1+\lambda_{P}\right) z_{i}^{I}\left(s_{i}^{I}, s_{i}^{E}\right)$ and $\left(1+\lambda_{P}\right) z_{i}^{E}\left(s_{i}^{I}, s_{i}^{E}\right)$. Volumes in $\mathrm{P}_{2 \mathrm{~S}}$ depend on the scenario considered. In 
the "Full Reversion" scenario, volumes are the same as in $\mathrm{P}_{2 \mathrm{NS}}$. In the "Full Retention" case, they are given by $\left(1+\lambda_{P}\right)\left(1-\gamma_{2}^{P}(e)\right) z_{i}^{I}\left(s_{i}^{I}, s_{i}^{E}\right)$ and $\left(1+\lambda_{P}\right)\left(z_{i}^{E}\left(s_{i}^{I}, s_{i}^{E}\right)+\gamma_{2}^{P}(e) z_{i}^{I}\left(s_{i}^{I}, s_{i}^{E}\right)\right)$.

The constant unit variable cost for CP for operator $j$ in zone $i$ is denoted by $f_{i}^{j}$. There is no need to distinguish upstream and downstream costs as no access is provided for this good. The competitors' price is $s_{i}^{E}=\left(1+m_{P}^{E}\right) f_{i}^{E}$.

The USP also faces a fixed cost $F$, due to being required to meet the USO.

The USP faces three price constraints, the second of which can take either of two forms.

The first constraint is a simple cap on the SP mail price set by the regulator: $p \leq \bar{p}$. (C1)

The second constraint is on the access prices that the USP can charge and is determined by the regulator. It can take either one of two forms: a pre-specified mark-up on the USP's downstream cost

$a_{i}=\left(1+m_{L}^{I}\right) d_{i}^{I},(\mathrm{C} 2 \mathrm{a})$

as applied in the numerical simulations in this paper ; or a margin squeeze constraint: the difference between the USP's BL price and access charge, in any zone $i$, must be at least equal to upstream FAC of the USP in that zone:

$$
q_{i}^{I}-a_{i} \geq b_{i}^{I}(1+\phi),(\mathrm{C} 2 \mathrm{~b}) \text { where } \phi \text { is the FAC factor. }
$$

The third constraint is that the difference between the (higher) SP mail price and the USP's (lower) BL price, in each zone, must be greater than the upstream preparation cost of the USP's BL final customers, $b^{p}$ : $p-q_{i}^{I}>b^{p}$ (C3), $i \in\{U, R\}$.

\section{2) Weighting of the two periods.}

$\mathrm{P}_{1}$ and $\mathrm{P}_{2}$ are both the last year of a five year regulatory cycle. In the case where a strike does occur in $\mathrm{P}_{1}$, the USP's profit levels in $\mathrm{P}_{1}$ and $\mathrm{P}_{2}$ are, respectively, $\pi_{1 S}$ and $\pi_{2 S}$. A linear progression is assumed from the final year of $\mathrm{P}_{1}$ to $\mathrm{P}_{2}$, and a yearly discount factor of $\delta$ where $\delta=1 /(1+r)$ and $r$ is the discount rate. The discounted value of the USP's profit over six years , evaluated in $\mathrm{P}_{1}$, is given by

$$
\pi_{1 S}+\sum_{i=1}^{5} \delta^{i}\left(\pi_{1 S}+i \frac{\pi_{2 S}-\pi_{1 S}}{5}\right)=w_{1} \pi_{1 S}+w_{2} \pi_{2 S}
$$

where

$$
w_{1}=\frac{5+4 \delta+3 \delta^{2}+2 \delta^{3}+\delta^{4}}{5}, w_{2}=\frac{1+2 \delta+3 \delta^{2}+4 \delta^{3}+5 \delta^{4}}{5} \delta .
$$

We proceed similarly with $\pi_{1 N S}$ and $\pi_{2 N S}$ (see equation (2)).

\section{3) Calibration for simulations.}

(A) Demand. For SP mail, BL and CP markets, when the retail price of the good considered is the same in both zones, the urban zone represents $80 \%$ of total volumes, and the rural zone $20 \%$. SP mail market: at a price of 1 , price elasticity is -0.2 (both zones) and total volume $2 \mathrm{bn}$ items. BL market, hypothetical monopoly setting: at a price of 0.4 , demand price elasticity of -0.4 (in both zones), and total volume of 7.5 billion items. With competition, displacement ratio - $\left[\partial y_{i}^{I}\left(q_{i}^{I}, q_{I}^{E}\right) / \partial q_{i}^{E}\right] /\left[\partial y_{i}^{E}\left(q_{i}^{I}, q_{I}^{E}\right) / \partial q_{i}^{E}\right]$ of 0.9 . Market share of $25 \%$ for competitors when 
$q_{i}^{I}=q_{i}^{E}=0.4$ and of 50\% when $q_{i}^{I}=0.4$ and $q_{i}^{E}=0.36$. In the CP market the USP price in the urban (resp., rural) area is 1.9 (resp., 2.4) and competitors are $10 \%$ more expensive than the USP while (i) the displacement ratio is 0.75 , (ii) the demand price elasticity is -0.2 , (iii) the USP volume is 0.4 (resp., 0.1), (iv) the USP's market share is $35 \%$. For equal USP and competitors' prices, the USP's market share is $10 \%$.

\section{(B) Costs (in $\left.\mathbf{P}_{\mathbf{1}}\right)$.}

SP mail market: unit variable cost $c_{i}$ of 0.57 in urban area $(i=U)$ and 0.72 in rural area $(i=R)$.

BL market: same upstream variable cost in both zones for both operators: $b_{U}^{I}=b_{U}^{E}=b_{R}^{I}=b_{R}^{E}=0.02$. Upstream preparation cost of the USP's BL final customers: $b^{p}=0.15$. USP's downstream cost: $d_{U}^{I}$ $=0.19$ and $d_{R}^{I}=0.34$. Competitors' downstream cost: $d_{U}^{E}=0.28$ and $d_{R}^{E}=0.74$.

CP market: unit variable costs: $f_{U}^{I}=1.14, f_{R}^{I}=1.44, f_{U}^{E}=2, f_{R}^{E}=2.6$.

USP: fixed cost of $F=2.4$; and FAC factor $\phi$ of $2 / 3$.

All (variable and fixed) USP costs decrease by $5 \mathrm{e} \%$ between $\mathrm{P}_{1}$ and $\mathrm{P}_{2}$.

\section{(C) Mark-ups.}

USP mark-up for access charge set by the regulator where constraint C2a applies: $m_{L}^{I}=0.1$.

Competitors' mark-up in BL market: $m_{L}^{E}=0.02$; and in CP market: $m_{P}^{E}=0.03$.

\section{(D) Exogenous variations in volumes}

Exogenous volume trend between $\mathrm{P}_{1}$ and $\mathrm{P}_{2}: \lambda_{L}=-0.2$ and $\lambda_{P}=0.2$.

Volume loss by the USP in the case of a strike in $\mathrm{P}_{1}$ as a proportion of the USP's pre-strike volume $\gamma_{1}^{L}(e)=0.04+4 e, \gamma_{2}^{L}(e)=0.01+e, \gamma_{1}^{P}(e)=0.08+8 e$ and $\gamma_{2}^{P}(e)=0.064+6.4 e$ where $e$ is expressed as a proportion (for example, $e=2 \%$ as $e=0.02$ ).

Volume loss by the USP for BL under the "Full Retention" scenario in $\mathrm{P}_{2 \mathrm{~s}}: \gamma_{2}^{L \mathrm{Ret}}(e)=0.03+3 e$. Volume diversion in $\mathrm{P}_{1 \mathrm{~s}}$ : $\beta_{1}^{L}=0.5$ and $\beta_{1}^{P}=0.8$; and for BL under the "Full Retention" scenario in $\mathrm{P}_{2 \mathrm{~S}}: \beta_{2}^{L}=2 / 3$.

(E) Discount factor for present value calculation

Discount rate of $10 \%: \delta=0.91 ; 5 \% \delta=0.95$

\section{References}

De Donder, P., Rodriguez F., and Soteri S. (2017). An examination of the links between postal price constraints, efficiency, competition and public welfare. P.L Parcu et al (eds.), The Changing Postal and Delivery Sector. Berlin : Springer 